\title{
Regulation of Placental Glucose Transfer and Consumption by Fetal Glucose Production
}

\author{
JANE E. DIGIACOMO AND WILLIAM W. HAY, JR. \\ From the Division of Perinatal Medicine, Department of Pediatrics, University of Colorado School of Medicine, \\ Denver, Colorado 80262
}

\begin{abstract}
We studied ten normoglycemic [maternal glucose $\left(G_{A}\right)=70 \mathrm{mg} / \mathrm{dL}$ ] and six insulin-induced hypoglycemic $\left(G_{A}=22 \mathrm{mg} / \mathrm{dL}\right)$ pregnant sheep to test the hypothesis that development of fetal glucose production (GPR) could help maintain fetal glucose concentration, limit uteroplacental-fetal glucose transfer (UPGT), and sustain uteroplacental glucose consumption (UPGC). Compared with the normoglycemic group, the hypoglycemic group demonstrated the following values: fetal glucose concentration $\left(G_{\mathrm{a}}\right)$ was $9.8 \pm 0.8 \mathrm{mg} / \mathrm{dL}(51 \%$ lower, $p<0.01)$, uterine glucose uptake (UtGU) was $16.7 \pm 1.4 \mathrm{mg} / \mathrm{min}(54 \%$ lower, $p<0.01)$, UPGT was $3.1 \pm 0.6 \mathrm{mg} / \mathrm{min}(81 \%$ lower, $p<$ $0.001)$, and UPGC was $13.6 \pm 1.4 \mathrm{mg} / \mathrm{min}(30 \%$ lower, $p$ $<0.05)$. The reduction in UPGC was significantly less $(p$ $<0.05$ ) than the reductions in UPGT and UtGU. Fetal glucose utilization rate (GUR) was decreased $20 \%(p<$ $0.05)$ to $3.99 \pm 0.35 \mathrm{mg} / \mathrm{min} / \mathrm{kg}$. A further decrease in GUR was prevented by the appearance of fetal GPR of $2.82 \pm 0.32 \mathrm{mg} / \mathrm{min} / \mathrm{kg}(p<0.05)$ compared with negligible GPR in the normoglycemic group. UPGT and UPGC in both groups were not influenced by maternal or fetal insulin infusions as long as $G_{a}$ did not change; however, fetal glucose infusion that increased $G_{a}$ increased UPGC in both groups. We conclude that, during chronic maternal hypoglycemia, increased fetal GPR limits the simultaneous decrease in fetal GUR and glucose concentration. By sustaining $G_{a}$ fetal GPR limits UPGT to a significantly greater extent than UtGU, diverting UtGU to UPGC. Thus, fetal GPR promotes placental as well as fetal metabolic autonomy when the maternal supply of glucose is reduced. (Pediatr Res 25:429-434, 1989)
\end{abstract}

\section{Abbreviations}

GPR, fetal glucose production

$G_{A}$, maternal glucose concentration

$G_{\mathrm{a}}$, fetal glucose concentration

GIR, glucose infusion rate

UGU, umbilical glucose uptake rate (equal to UPGT)

UPGT, uteroplacental-fetal glucose transfer

UPGC, uteroplacental glucose consumption

GUR, glucose utilization rate

In experiments designed to measure the effect of a reduced supply of glucose on fetal glucose metabolism, we observed in

Received October 13, 1988; accepted December 28, 1988.

Correspondence William W. Hay, Jr., M.D., Department of Pediatrics, Box B195, University of Colorado Health Sciences Center, 4200 East Ninth Avenue, Denver, CO 80262.

Supported by NIH Grant DK-35836, NIH Program Grant HD-00781, and NIH Center Grant HD-20761. Dr. DiGiacomo was supported by NIH Training Grant HD-07186. fasted, pregnant sheep that, at rates of net fetal glucose uptake less than half of normal, fetal glucose utilization significantly exceeded umbilical glucose uptake $(1,2)$. Similar preliminary studies showed the progressive development of a positive fetal hepatic vein-umbilical vein glucose concentration difference after three $\mathrm{d}$ of fasting-induced maternal and fetal hypoglycemia (3). We interpreted these observations as evidence of GPR by the fetus itself. As previous studies $(4,5)$ found negligible rates of fetal GPR during maternal normal glycemia, an increased fetal GPR presumably serves to maintain the rate of fetal glucose utilization when maternal glucose supply decreases. It is not obvious, however, how fetal GPR might also affect placental glucose flux. This is an important concern because in recent experiments using fetal glucose and insulin infusions we observed that changes in fetal glucose concentration significantly altered UPGT and UPGC independent of fetal insulin concentration, maternal glucose concentration, and maternal glucose supply to the placenta (6). These observations suggested that fetal GPR could regulate placental glucose flux via effects on fetal glucose concentration. This mechanism would provide relative autonomy of fetal and placental metabolism at times when maternal glucose supply is limited.

To test this hypothesis, we infused insulin into pregnant sheep during the last $20 \%$ of gestation, producing periods of up to 3 wk of maternal hypoglycemia. During these periods, fetal and placental glucose metabolism were studied using combined Fick principle, glucose clamp, and tracer techniques. The present report documents the development of fetal GPR at low levels of maternal glucose concentration and maternal glucose supply to the fetus and describes how fetal GPR affects placental glucose transfer and consumption independent of maternal regulation.

\section{MATERIALS AND METHODS}

Animal preparation. Experiments were conducted in pregnant Columbia-Rambouillet ewes, each carrying a single fetus. The ewes were fasted for two days prior to surgery. Surgery was performed at approximately $115 \mathrm{~d}$ of gestation under intravenous pentobarbital sedation $(5.0 \mathrm{mg} / \mathrm{kg})$ and pontocaine spinal anesthesia $(6.0 \mathrm{mg}$ in hypertonic glucose). Maternal catheters for infusion were placed into a femoral vein through a groin incision. Maternal catheters for sampling included a femoral artery catheter (placed via the groin incision), and after a midline laparotomy was performed, a uterine venous catheter was placed into the main uterine vein draining the pregnant uterine horn containing the study fetus. A standard hysterotomy was performed, and catheters for fetal infusions were placed into fetal femoral veins via hindlimb pedal veins. Additional catheters for fetal blood sampling were placed in the fetal abdominal aorta via a hindlimb pedal artery and into the common umbilical vein. All catheters were tunneled subcutaneously through a flank incision on the ewe and kept within a plastic pouch attached to the ewe's skin. The catheters were flushed every other $d$ with heparinized 
$0.9 \% \mathrm{wt} / \mathrm{vol}$ sodium chloride (30 U heparin/mL $0.9 \%$ sodium chloride). Each ewe was allowed to recover postoperatively for 2-3 d until behavior, food intake, and water intake were normal. The ewes were kept in carts and given an ad libitum diet of alfalfa pellets, water, and mineral supplements. They were kept in a room with the temperature controlled between 10 and $20^{\circ} \mathrm{C}$. At least two sheep were always kept together for company.

Study design. One group of 10 ewes was used for control studies and did not receive any intravenous infusions except at the time of study. Arterial blood was sampled daily for maternal and fetal glucose concentrations. A second group of six ewes received a continuous infusion of insulin intravenously for approximately $3 \mathrm{wk}$. During this time, maternal arterial and fetal arterial blood were sampled once or twice daily for measurement of glucose and insulin concentrations with subsequent adjustment of the insulin infusion rate to achieve a desired maternal arterial blood glucose concentration of approximately $20-25 \mathrm{mg} /$ $\mathrm{dL}$, an estimated reduction of $50 \%$ from normal.

Studies were conducted in each ewe at least 2 wk after establishing the desired level of maternal arterial glucose concentration. At the start of each study, a continuous infusion of antipyrine $(10 \% \mathrm{wt} / \mathrm{vol}$ in normal saline, approximately $3.0 \mathrm{mg} /$ $\mathrm{min} / \mathrm{kg}$ ) was given to each fetus via a saphenous vein catheter to measure umbilical and uterine blood flow. At the same time, each fetus received a primed, constant infusion of [U $\left.-{ }^{14} \mathrm{C}\right]$ glucose $(\sim 40 \mu \mathrm{Ci} / \mathrm{kg}$ estimated fetal wt followed by $\sim 0.4 \mu \mathrm{Ci} / \mathrm{min} / \mathrm{kg})$ to measure fetal glucose utilization rate (5). Blood samples were drawn from the uterine vein, maternal artery, fetal aorta, and common umbilical vein simultaneously at $90,100,110$, and 120 min of the study. Whole blood samples for blood glucose, ${ }^{14} \mathrm{C}$ glucose, and antipyrine and for plasma insulin concentrations were drawn into plastic syringes lined with EDTA. Plasma for insulin assay was separated in a refrigerated centrifuge and stored at $-70^{\circ} \mathrm{C}$ until time of assay. Whole blood samples for oxygen content analysis were drawn into glass capillaries lined with dried sodium heparin and sodium fluoride.

After the control period, two different fetal clamp studies were performed in both control and hypoglycemic animals on separate days. These studies were performed at least $2 \mathrm{~d}$ apart in random sequence. For the euglycemic-hyperinsulinemic clamp, insulin (pure pork insulin, Eli Lilly Corp., Indianapolis, IN, diluted in $30 \mathrm{~mL} 0.9 \% \mathrm{wt} / \mathrm{vol}$ sodium chloride and $7 \mathrm{~mL}$ maternal sheep plasma) was infused into each fetus via a saphenous vein catheter at approximately $1.0 \mathrm{mU} / \mathrm{min} / \mathrm{kg}$ estimated fetal wt after a prime dose of $40 \mathrm{mU} / \mathrm{kg}$. At $10 \mathrm{~min}$ after the insulin infusion was started, dextrose infusion (10\% wt/vol in water, Travenol Laboratories, Inc., Deerfield, IL) was added, starting at $2.5 \mathrm{mg} / \mathrm{min} /$ $\mathrm{kg}$ estimated fetal wt. Fetal arterial blood glucose concentration was then sampled at 10 -min intervals, and the dextrose infusion rate was adjusted to maintain the mean fetal arterial blood glucose concentration of the control period. The adjustment in fetal GIR was made according to the following algorithm $(7,8)$ :

New GIR (mg/min)

$=$ Previous GIR $\times \mathrm{Gd} / \mathrm{Gi}+\{[(\mathrm{Gd}-\mathrm{Gi})(4)(\mathrm{wt})] / 10 \mathrm{~min}\}$

where $\mathrm{Gd}$ is the desired fetal arterial blood glucose concentration $(\mathrm{mg} / \mathrm{dL}), \mathrm{Gi}$ is the glucose concentration at any time " $\mathrm{i}, ", 4$ is the estimated fetal glucose space $(\mathrm{dL} / \mathrm{kg})$, wt is the estimated fetal wt $(\mathrm{kg})$ at study, and $10 \mathrm{~min}$ converts the pool correction factor in brackets to a rate change over ten min. Blood samples identical to the control period were obtained at 120,130, 140, and $150 \mathrm{~min}$ after the start of the insulin infusion.

For the hyperglycemic clamp, no insulin infusion was used. Fetuses received a dextrose infusion as described above, with the exception that the infusion rate was adjusted to maintain the fetal arterial blood glucose concentration at approximately 40 $\mathrm{mg} / \mathrm{dL}(\sim 2$ times control) in group 1 fetuses and at approximately $20 \mathrm{mg} / \mathrm{dL}$ ( "normal" glucose concentration) in group 2 fetuses. Fetal insulin concentration was not clamped. There- fore, insulin concentration could change in response to the change in glucose concentration. Samples identical to those drawn during the control period were obtained at 100,110,120, and $130 \mathrm{~min}$ after starting the dextrose infusion. Fetal blood samples were replaced by equal vol of maternal blood immediately after sampling.

At the end of the study, the ewe and fetus were killed with a rapid intravenous infusion of T-61 euthanasia solution (Taylor Pharmaceutical Co., Decatur, IL). An autopsy was performed to obtain fetal wt and placental cotyledonary number and wt. The study was approved by the University of Colorado Health Sciences Center Institutional Animal Care and Use Committee.

Chemical and analytical methods. Whole blood glucose concentration was measured by a glucose oxidase method (Sigma Chemical Co., St. Louis, MO). Whole blood $\left[{ }^{14} \mathrm{C}\right]$ glucose was measured using an ion exchange chromatography method (5). Whole blood antipyrine concentration was measured by a Technicon Autoanalyzer according to the method described by Meschia et al. (9) and Wilkening et al. (10). Blood oxygen capacity and percentage of oxygen saturation were measured with the Radiometer OSM-2 hemoximeter (Copenhagen, Denmark) to calculate blood oxygen content. Maternal arterial blood glucose concentration for maintaining the glucose clamps was measured with a Yellow Springs Instrument Co. Model 23A glucose analyzer (Yellow Springs, $\mathrm{OH}$ ). The glucose analyzer was calibrated to an accuracy of $\pm 1.0 \mathrm{mg} / \mathrm{dL}$. A standard with the concentration of glucose close to the desired value in the blood was analyzed before each blood sample and used to keep the instrument calibrated throughout the study. Maternal and fetal plasma insulin concentrations were measured by a double antibody method using a kit from Cambridge Medical Diagnostics, Inc. (Billerica, MA) and ovine insulin standards from Eli Lilly.

Calculations. Umbilical blood flow was calculated by the steady-state diffusion technique $(9,10)$. Net glucose and oxygen uptakes by the uterus, the fetus (equal to the net transfer from uteroplacenta to fetus), and the uteroplacenta (equal to net uteroplacental consumption) were calculated by the Fick principle as previously described (1). Fetal glucose utilization rate was calculated as the net fetal $\left[{ }^{14} \mathrm{C}\right]$ glucose uptake rate divided by fetal arterial blood glucose sp act (5). Net fetal GPR was calculated as the difference between fetal glucose utilization rate and net fetal glucose uptake by the umbilical circulation in the control period or total glucose entry (UGU + GIR) in the insulinglucose clamp periods (4). These calculations used the mean blood flow and mean arteriovenous substrate concentration differences of the four blood samples during the $30 \mathrm{~min}$ of each study period. Fetal wt at the time of study was estimated using the formula (8):

$\log w \mathrm{t}(\mathrm{kg})=-0.951+0.0543$ age $(\mathrm{d})$

-0.000155 [age (days) $]^{2}$

Plasma glucose concentrations were calculated from the measured whole blood glucose concentrations using the following formulas:

$$
\begin{aligned}
& \text { for maternal values: } \mathrm{P}=(\mathrm{W}+2.0 \mathrm{H}) /(1-0.87 \mathrm{H}) \\
& \text { for fetal values: } \\
& \qquad \mathrm{P}=(\mathrm{W}+3.3 \mathrm{H}) /(1-0.24 \mathrm{H})
\end{aligned}
$$

where $P$ is concentration of glucose in plasma $(\mathrm{mg} / \mathrm{dL}), \mathrm{W}$ is whole blood glucose concentration $(\mathrm{mg} / \mathrm{dL})$, and $\mathrm{H}$ is hematocrit expressed as a fraction (11).

Statistics. Steady state was defined during each 30 -min sampling period as $<5 \%$ variation of individual values around the period mean value with no consistent trend to increase or decrease. The sampling period mean value was used for intra- and interanimal comparisons using paired and unpaired $t$ tests and ANOVA. Regression analysis used the standard least squares method for linear correlation. 


\section{RESULTS}

Daily mean maternal and fetal arterial blood glucose concentrations before studies are shown in Figure 1. Studies were conducted on 19,20 , or 21 of maternal insulin infusion in the hypoglycemic groups and at $134 \pm 2 \mathrm{~d}$ gestation in each group. Fetal wt at autopsy was $3.5 \pm 0.2 \mathrm{~kg}$ in group 1 (control) and 2.7 $\pm 0.2 \mathrm{~kg}$ in group 2 (hypoglycemic) (significantly different, $p<$ $0.005)$. Placental cotyledonary number and wt were $78 \pm 6$ and
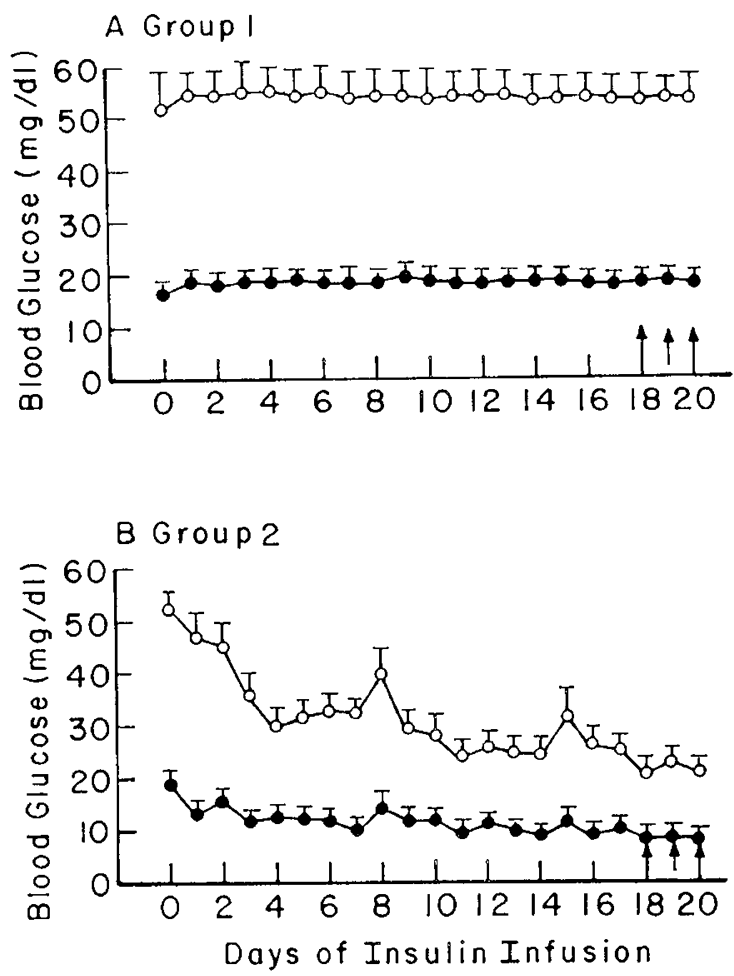

Fig. 1. Daily maternal $(O)$ and fetal $(\bullet)$ blood glucose concentrations (mean $\pm \mathrm{SEM}$ ) in normoglycemic control animals ( $A$, group 1$)$ and in hypoglycemic group 2 animals $(B)$. Arrows indicate d of study among the animals.
$289 \pm 18$, respectively, for the control group ( $n=6$ of 10$)$ and $88 \pm 6$ and $260 \pm 26$, respectively, for the hypoglycemic group $(n=4$ of 6$)$. These values were not different between control and hypoglycemic groups. Uterine and umbilical blood flows were comparable between the two groups and did not change significantly during the insulin or insulin plus glucose infusions.

Glucose and insulin concentrations are presented in Table 1. The control period maternal arterial plasma glucose concentration was reduced by $51.8 \%(p<0.001)$ in group 2 compared with the normoglycemic animals in group 1 . The control period fetal arterial plasma glucose was reduced by $41.7 \%(p<0.001)$ in group 2 compared with group 1 . Fetal arterial plasma insulin concentration was reduced by $63.6 \%$ in group $2(p<0.01)$.

Blood oxygen content and oxygen fluxes are shown in Table 2. There was no significant difference between group 1 and group

Table 1. Plasma glucose and insulin concentrations*

\begin{tabular}{|c|c|c|c|}
\hline & Control & $\begin{array}{l}\text { Euglycemic } \\
\text { insulin clamp }\end{array}$ & $\begin{array}{l}\text { Hyperglycemic } \\
\text { glucose clamp }\end{array}$ \\
\hline \multicolumn{4}{|c|}{ Group 1, normal glycemic, $n=10$} \\
\hline $\begin{array}{l}\text { Glucose maternal artery } \\
(\mathrm{mg} / \mathrm{d} \mathbf{L}, \text { plasma })\end{array}$ & $70.1(5.0)$ & $71.2(5.1)$ & $71.5(5.1)$ \\
\hline $\begin{array}{l}\text { Glucose fetal artery (mg/ } \\
\text { dL, plasma) }\end{array}$ & $20.6(0.9)$ & $19.2(1.3)$ & $52.0(2.0)$ \\
\hline $\begin{array}{l}\text { Insulin maternal artery } \\
(\mu \mathrm{U} / \mathrm{mL}, \text { plasma })\end{array}$ & $22(2)$ & $21(3)$ & $23(4)$ \\
\hline $\begin{array}{l}\text { Insulin fetal artery }(\mu \mathrm{U} / \\
\mathrm{mL} \text {, plasma) }\end{array}$ & $11(1)$ & $38(4)$ & $40(6)$ \\
\hline \multicolumn{4}{|c|}{ Group 2, hypoglycemic, $n=6$} \\
\hline $\begin{array}{l}\text { Glucose maternal artery } \\
\text { (mg/dL, plasma) }\end{array}$ & $33.8+(1.8)$ & $28.9 \dagger(3.6)$ & $32.9 \dagger(0.4)$ \\
\hline $\begin{array}{l}\text { Glucose fetal artery (mg/ } \\
\text { dL, plasma) }\end{array}$ & $12.0 \dagger(1.0)$ & $10.3 \dagger(1.3)$ & $23.6 \dagger \ddagger(0.2)$ \\
\hline $\begin{array}{l}\text { Insulin maternal artery } \\
\qquad(\mu \mathrm{U} / \mathrm{mL}, \text { plasma })\end{array}$ & $80 \dagger(10)$ & $70 \dagger(10)$ & $68 \dagger(12)$ \\
\hline $\begin{array}{l}\text { Insulin fetal artery }(\mu \mathrm{U} / \\
\mathrm{mL} \text {, plasma) }\end{array}$ & $4 \dagger(1)$ & $84 \dagger+(16)$ & $48 \ddagger(17)$ \\
\hline
\end{tabular}

$*$ Values are means \pm SEM.

$\dagger$ Different from normal glycemic group, $p<0.05$.

$\$$ Different from control period, $p<0.05$.

Table 2. Fetal blood oxygen content and oxygen fluxes in the uteroplacenta and fetus*

\begin{tabular}{|c|c|c|c|}
\hline & Control & $\begin{array}{c}\text { Euglycemic } \\
\text { insulin clamp }\end{array}$ & $\begin{array}{l}\text { Hyperglycemic } \\
\text { glucose clamp }\end{array}$ \\
\hline \multicolumn{4}{|l|}{ Group 1, normal glycemic, $n=10$} \\
\hline $\begin{array}{l}\text { Oxygen content, fetal artery (mM, } \\
\text { blood) }\end{array}$ & $3.67(0.11)$ & $2.68 \dagger(0.13)$ & $3.03+(0.15)$ \\
\hline Oxygen uptake, uterine $(\mathrm{mmol} / \mathrm{min})$ & $1.88(0.13)$ & $1.82(0.16)$ & $1.97(0.17)$ \\
\hline $\begin{array}{l}\text { Oxygen uptake, uteroplacenta (mmol/ } \\
\text { min) }\end{array}$ & $0.73(0.06)$ & $0.64(0.09)$ & $0.67(0.10)$ \\
\hline $\begin{array}{l}\text { Oxygen uptake, fetus (umbilical) } \\
(\mathrm{mmol} / \mathrm{min}) \\
(\mathrm{mmol} / \mathrm{min} / \mathrm{kg})\end{array}$ & $\begin{array}{l}1.15(0.07) \\
0.33(0.03)\end{array}$ & $\begin{array}{l}1.18(0.10) \\
0.34(0.03)\end{array}$ & $\begin{array}{l}1.30(0.07) \\
0.37(0.02)\end{array}$ \\
\hline \multicolumn{4}{|l|}{ Group 2, hypoglycemic, $n=6$} \\
\hline $\begin{array}{l}\text { Oxygen content, fetal artery (mM, } \\
\text { blood) }\end{array}$ & $3.77(0.22)$ & $2.57 \dagger(0.16)$ & $3.02 \dagger(0.46)$ \\
\hline Oxygen uptake, uterine $(\mathrm{mmol} / \mathrm{min})$ & $1.45 \ddagger(0.07)$ & $1.48 \div(0.17)$ & $1.60 \ddagger(0.14)$ \\
\hline $\begin{array}{l}\text { Oxygen uptake, uteroplacenta (mmol/ } \\
\text { min) }\end{array}$ & $0.61(0.04)$ & $0.53(0.14)$ & $0.70(0.06)$ \\
\hline $\begin{array}{l}\text { Oxygen uptake, fetus (umbilical) } \\
(\mathrm{mmol} / \mathrm{min}) \\
(\mathrm{mmol} / \mathrm{min} / \mathrm{kg})\end{array}$ & $\begin{array}{l}0.82 \ddagger(0.05) \\
0.31(0.02)\end{array}$ & $\begin{array}{l}0.93 \ddagger(0.07) \\
0.35(0.03)\end{array}$ & $\begin{array}{l}0.94 \ddagger(0.10) \\
0.36(0.04)\end{array}$ \\
\hline
\end{tabular}

$*$ Values are means \pm SEM.

$\uparrow$ Different from control period, $p<0.05$.

$\ddagger$ Different from normal glycemic group, $p<0.05$. 
2 mean values for arterial blood oxygen content. However, fetal arterial oxygen content decreased significantly $(p<0.05)$ in both groups during the euglycemic hyperinsulinemic clamp and the hyperglycemic glucose clamps. Total net oxygen uptake rates by the uterus and the fetus were lower in group $2(p<0.05)$ but were not different when calculated on a wt-specific basis (fetal wt for fetal oxygen uptake, fetal plus placental cotyledonary wt for uterine oxygen uptake). Uteroplacental oxygen consumption rates were not different between the two groups overall or per $g$ of placental wt. Net oxygen uptake rates by the uterus, fetus, and uteroplacenta did not change significantly during the hyperinsulinemic-euglycemic insulin clamp or the hyperglycemic glucose clamp.

Glucose fluxes are presented in Table 3 and Figure 2. Control period uterine glucose uptake was reduced by $54.0 \%$ in group 2 . Fetal glucose uptakes were reduced by $75.7 \%$ and net uteroplacental glucose uptake (consumption) was reduced by $30.6 \%$. Fetal glucose utilization rate was $19.6 \%$ lower in group 2 ( $p<$ 0.05 ) compared with group 1. Calculated fetal GPR increased from the negligible value in group 1 to nearly $3.0 \mathrm{mg} / \mathrm{min} / \mathrm{kg}$ in group 3 (GPR different from $0, p<0.01$ ), accounting for $70.7 \%$ of fetal GUR.

During the euglycemic hyperinsulinemic clamps in each group there were no significant changes from the control period in maternal and fetal arterial plasma glucose concentrations or net uterine, fetal, and uteroplacental glucose uptake rates. During the hyperglycemic fetal glucose clamps in group 1, maternal glucose concentration did not change significantly, but uterine uptake was reduced by $37 \%(p<0.01)$ from the control period. Uteroplacental glucose consumption increased by $61 \%(p<$ 0.01 ), equal to the sum of the uterine glucose uptake and the net glucose flux from fetus to placenta. Fetal GUR increased $31.2 \%$ $(p<0.05)$ from the euglycemic, insulin clamp period and $81.3 \%$ $(p<0.01)$ from the control period. During the hyperglycemic glucose clamps in group 2 animals, there was no change in maternal arterial plasma glucose concentration or uterine glucose uptake. UPGC increased $78.0 \%(p<0.01)$ above the control period and $89.5 \%(p<0.01)$ above the euglycemic, insulin infusion period. Fetal glucose concentration was slightly $(14.6 \%)$ but significantly $(p<0.05)$ higher than that of the control period mean value in the group 1 animals, as was the uteroplacental glucose consumption $(23.6 \%, p<0.05)$. The latter was accounted for by the sustained uterine glucose uptake and the negative umbilical glucose uptake. Fetal GUR increased $46.0 \%(p<.001)$ from the euglycemic, insulin clamp period and $80.7 \%(p<0.01)$ from the control period.

Uteroplacental glucose consumption averaged $53.8 \%$ of net uterine glucose uptake in group 1 in the control period and $81.3 \%$ in group $2(p<0.01)$. These proportions were not changed during the euglycemic clamps, but hyperglycemia in the fetuses in both groups increased UPGC to $100 \%$ of net uterine uptake: $72.9 \%$ from the maternal circulation, $27.1 \%$ from the fetus in group $1 ; 66.5 \%$ from the maternal circulation, $33.5 \%$ from the fetus in group 2 . These proportions were not significantly different between groups.

\section{DISCUSSION}

In the present study, sustained maternal hyperinsulinemia in pregnant sheep significantly reduced maternal arterial glucose concentration, the uptake of glucose by the uterus, the net consumption of glucose by the uteroplacenta, the transfer of glucose to the fetus, fetal glucose and insulin concentrations, and fetal glucose utilization rate. The reductions in maternal glucose concentration and uterine glucose uptake were disproportionately greater than the other glucose decreases. The reason for these discrepancies appears to be the development of GPR by the fetus itself, which sustained fetal glucose concentration and fetal glucose utilization by the addition of glucose molecules to the fetal glucose pool. The relative increase in fetal glucose concentration also reduced the maternal-fetal arterial glucose gradient to a greater extent than that produced by the fall in maternal glucose concentration. Consequently, net glucose transfer to the fetus (measured as net umbilical glucose uptake) was reduced by a larger fraction than the uterine glucose uptake, providing more glucose for uteroplacental consumption. The measured decrease in placental transport of glucose to the fetus and the increase in net uteroplacental glucose consumption represent, therefore, unique demonstrations that fetal GPR can contribute to maintenance of fetal glucose concentration (and

Table 3. Uteroplacental and fetal glucose fluxes*

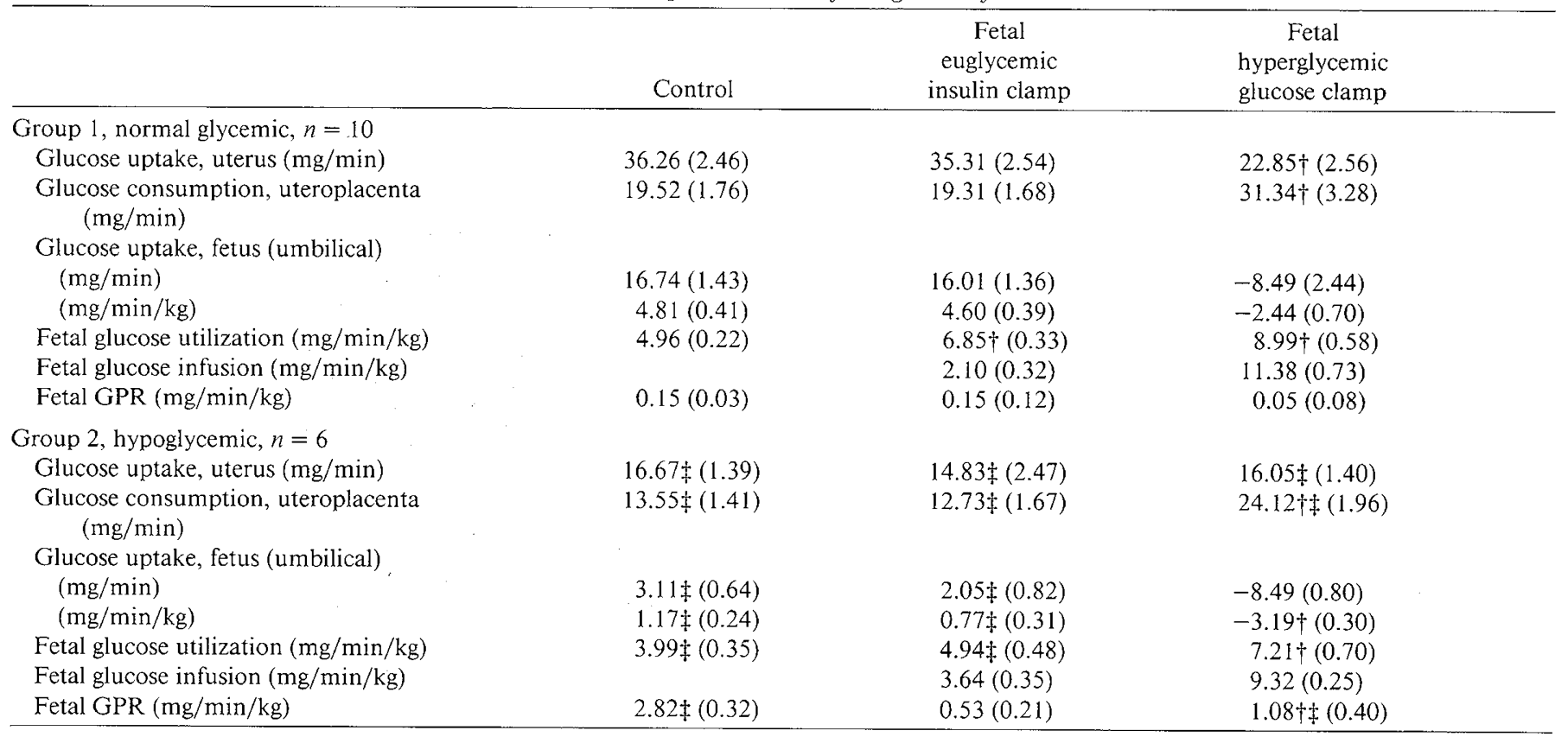

$*$ Values are means \pm SEM

$\uparrow$ Different from control period, $p<0.05$.

$\ddagger$ Different from normal glycemic group, $p<0.05$. 

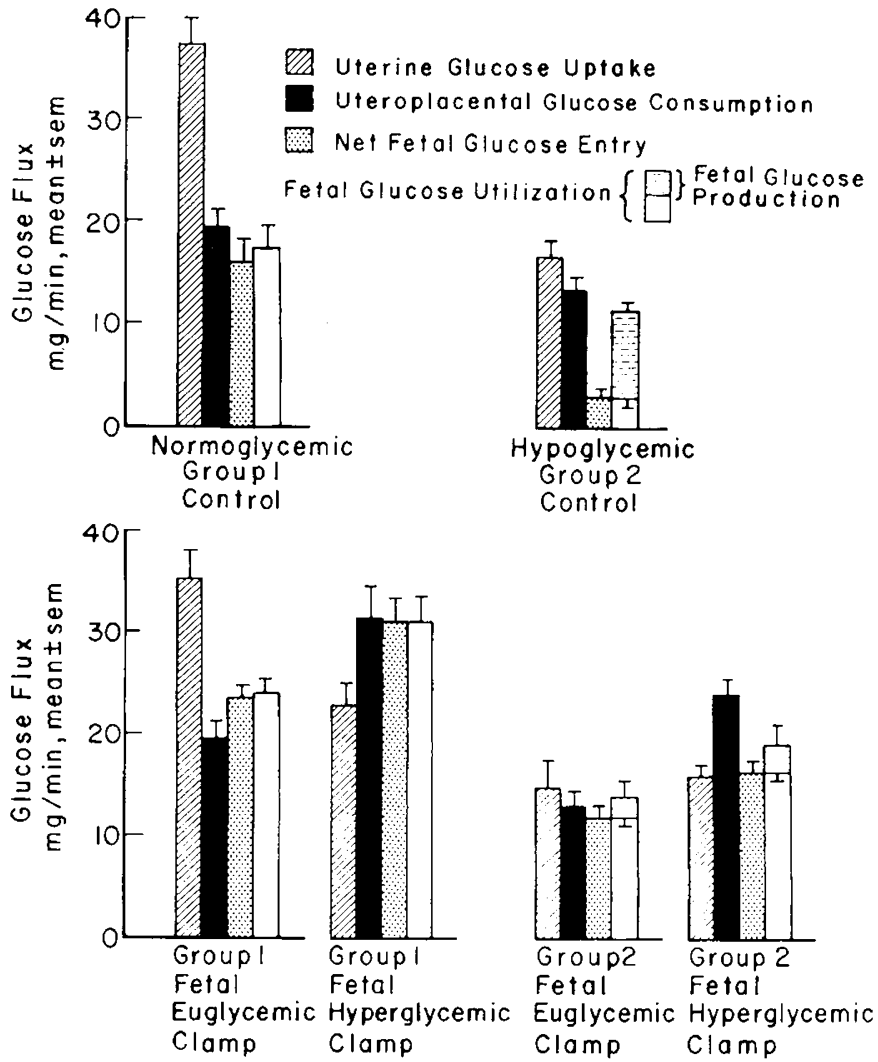

Fig. 2. Glucose flux rates in the normoglycemic, group 1 animals (left) and the hypoglycemic, group 2 animals (right) during control (top) and euglycemic and hyperglycemic fetal clamp (bottom) periods. Net fetal glucose entry is equal to net UGU in the control periods and to UGU plus GIR in the clamp periods.

the maternal-fetal glucose gradient) and thus regulate the exchange of glucose between placenta and fetus as well as the consumption of glucose by the uteroplacental tissues.

Our previous study (6) using glucose infusions to alter fetal glucose concentrations also demonstrated that fetal glucose concentration affected uteroplacental glucose consumption. At physiologic concentrations we showed that UPGC was directly related to $G_{a}$. This effect was independent of maternal glucose concentration and uterine glucose supply from the uterine circulation. It appears from the present study that an increase in $G_{a}$ relative to $G_{A}$ affects the distribution of glucose molecules entering the uteroplacenta by reducing the transfer of glucose to the fetus, thus increasing the availability of glucose for placental consumption. Under these conditions, fetal glucose concentration contributes independently to the net determination of the intratrophoblast glucose supply and most likely the intratrophoblast glucose concentration, both of which appear to have direct effects on uteroplacental glucose consumption. The effect of the intratrophoblast glucose supply on UPGC has been suggested previously in studies by Crandell et al. (12) as well as investigations in our laboratory (13) in which $G_{a}$ and $G_{A}$ were increased by a maternal glucose infusion that increased intratrophoblast glucose supply.

Although the present study is unique in its demonstration of the role of fetal GPR in regulation of fetal glucose concentration, earlier investigators have suggested that placental glucose flux is controlled to some degree by $\mathrm{G}_{\mathrm{a}}$. In 1952, Widdas (14) proposed that the placental transfer of glucose to the fetus was dependent on a complex function of the maternal-fetal arterial plasma glucose gradient:

$$
\mathrm{UPGT}=\mathrm{K}_{1}\left\{\left[\mathrm{G}_{\mathrm{A}} /\left(\mathrm{G}_{\mathrm{A}}+\mathrm{K}_{2}\right)\right]-\left[\mathrm{G}_{\mathrm{a}} /\left(\mathrm{G}_{\mathrm{a}}+\mathrm{K}_{2}\right)\right]\right\}
$$

Simmons et al. (15) provided a unique set of experimental data in pregnant sheep which supported the validity of this equation but also demonstrated that the expression had a negative $y$ - intercept; that is, as $G_{a}$ approached $G_{A}$, UPGT was reduced to 0 , then ultimately reversed direction such that net glucose transfer was from fetus to uteroplacenta. Thus,

$$
\mathrm{UPGT}=\mathrm{K}_{1}\left\{\left[\mathrm{G}_{\mathrm{A}} /\left(\mathrm{G}_{\mathrm{A}}+\mathrm{K}_{2}\right)\right]-\left[\mathrm{G}_{\mathrm{a}} /\left(\mathrm{G}_{\mathrm{a}}+\mathrm{K}_{2}\right)\right]\right\}-\mathrm{q}_{\mathrm{P}}
$$

where $-q_{P}$ is the net rate of glucose transferred from fetus to placenta when $G_{a}=G_{A}$. In these studies, $G_{A}$ and $G_{a}$ were regulated by the infusion of glucose into the mother and/or the fetus. More recently, we studied UPGT at several maternal-fetal glucose gradients established by fixing $G_{A}$ and infusing dextrose into the fetus to produce discrete steady-state glucose concentrations in the physiologic range. These studies demonstrated an inverse relationship between $\mathrm{G}_{\mathrm{a}}$ and UPGT (6). Together these earlier observations provided evidence defining the specific role of fetal glucose concentration in determining the maternal-fetal glucose gradient and thereby regulating the net transfer of glucose from the uterine to the umbilical circulation by the placenta. The data in the present study confirm the effect of $G_{a}$ on UPGT. Furthermore, they uniquely demonstrate that this interaction is regulated by fetal physiologic mechanisms and is not a phenomenon seen only during experimental manipulation with exogenous fetal glucose and insulin infusions.

In addition to the effects on $G_{a}$, UPGT, and UPGC, fetal GPR also provided glucose to sustain fetal glucose utilization rate. In the hypoglycemic group, UPGT was only $19 \%$ of the value in the control group; at the same time fetal GUR was $80 \%$ of the control value. This relatively high level of GUR during hypoglycemia exceeds by 1.5 -fold the value estimated from our previous study of the effect of $G_{a}$ and $I_{a}$ on fetal GUR (4). In that study, fetal GPR was not present. Thus, fetal GPR serves three purposes: l) it provides glucose molecules to sustain fetal glucose concentration when maternal glucose supply decreases markedly; 2) by maintaining $G_{a}$, it reduces the placental transfer of glucose to the fetus, making maternal glucose more available for placental consumption; and 3) it provides glucose molecules for fetal glucose utilization. All of these effects have been demonstrated using an exogenous infusion of glucose into the fetus (4). In the present study, similar effects were produced by physiologic changes in fetal metabolism. The end result is that, in the presence of a reduced supply of glucose from the mother, the fetus has the capacity to become more autonomous, reducing the demand on maternal glucose supply while continuing to meet the glucose needs of itself and its essential supply organ, the placenta. The absence of any significant change in oxygen supply suggests that the development of fetal GPR is a response to reduced glucose supply and not to oxygen deficit, an observation in keeping with the idea that the fetus can vary its rates of substrate metabolism in response to selective nutritional deprivation while maintaining normal rates of oxidative metabolism. The specific changes in substrate metabolism have not been documented experimentally. However, it is likely that during severe maternal hypoglycemia fetal amino acid metabolism is altered, increasing the availability of the glucogenic amino acids (e.g. alanine) for gluconeogenesis. Studies of leucine metabolism in fetal lambs after fasting-induced maternal and fetal hypogly. cemia suggest that increased amino acid availability is due to increased protein degradation rather than decreased protein synthesis (16). This finding is supported further by studies of overall protein turnover in fetal rats during maternal starvation, which similarly found no change in the rate of protein synthesis but an increase in the rate of protein degradation (17).

Although several studies $(4,6,18)$ have demonstrated convincingly the absence of any effect of maternal or fetal insulin concentration on placental glucose uptake, transfer, or consumption, one group has published data recently from which they drew a contradictory conclusion. During fetal insulin infusion under nonsteady-state conditions of maternal and fetal glucose concentration and placental glucose flux, Bloch et al. (19) reported an apparent increase in the net extraction of tracer glucose from the umbilical circulation by the placenta. They suggested that this finding could be due to an insulin effect on placental 
glucose uptake. Therefore, in the present study a euglycemic, hyperinsulinemic insulin clamp was performed in both control and hypoglycemic fetuses to assess possible effects of insulin on placental metabolism under steady-state conditions. In both cases, fetal arterial glucose concentration was maintained with tight precision at the control period mean glucose concentration. There was no change in placental-fetal glucose exchange in response to the hyperinsulinemia, and the tracer glucose distribution was increased into the fetus and away from the uteroplacenta in all cases. Thus, as in our previous studies, there is no effect of relative fetal hyperinsulinemia in placental flux of either tracer or unlabeled glucose. Only a change in fetal glucose concentration relative to the maternal glucose concentration has an effect on placental-fetal glucose exchange. This conclusion is further supported by the glucose infusion period in the normal and the hypoglycemic fetuses. In this situation, the increase in fetal glucose concentration relative to the maternal glucose concentration suppressed UPGT to the fetus and, in fact, reversed the flux to a net fetal-to-placental transfer. UPGC was increased at the same time even though the uterine glucose supply was unaffected.

During the hyperinsulinemic euglycemic clamp studies in group 2, $\mathrm{G}_{\mathrm{a}}$ and umbilical glucose uptake remained at control values. Therefore, the hypoglycemic stimulus to fetal GPR still existed concomitantly with hyperinsulinemia, which should have maintained a suppressive effect on glucogenesis. Under these conditions the calculated GPR was suppressed to a value not significantly different from 0 . In addition, the insulin-enhanced GUR was accounted for by the rate of fetal intravenous glucose infusion. Thus, the hyperinsulinemic clamp experiments added further confirmation that the calculated GPR, although an indirect measurement, was valid.

In conclusion, the results of the present study demonstrate the development of fetal GPR in response to maternal hypoglycemia, fetal hypoglycemia, and a reduced placental transfer of glucose to the fetus. The fetal GPR helps to maintain fetal glucose concentration and fetal glucose utilization rate. The relatively maintained fetal glucose concentration in turn maintains a lower maternal-fetal glucose gradient, limiting UPGT to the fetus and diverting uterine glucose uptake to uteroplacental glucose consumption. Thus, fetal GPR provides an autonomous means by which the fetus sustains fetal and placental oxidative metabolism and glucose utilization in the presence of a reduced supply of glucose from the mother.

\section{REFERENCES}

1. Hay WW Jr, Sparks JW, Wilkening RB, Battaglia FC, Meschia G 1984 Fetal glucose uptake and utilization as functions of maternal glucose concentration. Am J Physiol 246:E237-E242

2. Hay WW Jr, Sparks JW, Wilkening RB, Battaglia FC, Meschia G 1983 Partition of maternal glucose production between conceptus and maternal tissues in sheep. Am J Physiol 245:E347-E350

3. Sparks JW, Hay WW Jr, Meschia G, Battaglia FC 1982 Fetal liver metabolism in the unstressed fetal lamb: experience with a chronic indwelling hepatic venous catheter. Pediatr Res 15(suppl): 118 (abstr)

4. Hay WW Jr, Meznarich HK, DiGiacomo JE, Hirst K, Zerbe G 1988 Effects of insulin and glucose concentrations on glucose utilization in fetal sheep. Pediatr Res 23:381-387

5. Hay WW Jr, Sparks, JW, Quissell BJ, Battaglia FC, Meschia G 1981 Simultaneous measurements of umbilical uptake, fetal utilization rate, and fetal turnover rate of glucose. Am J Physiol 240:E662-E668

6. Hay WW Jr 1987 Regulation of ovine placental glucose consumption (PGU) Physiologist 30:174 (abstr 43.12)

7. DeFronzo RA, Tobin JD, Andres R 1979 Glucose clamp technique: a method for quantifying insulin secretion and resistance. Am J Physiol 237:E214E223

8. Hay WW Jr, Meznarich HK, Sparks JW, Battaglia . 'C, Meschia G 1985 Effect of insulin on glucose uptake in near-term fetal lambs. Proc Soc Exp Biol Med 178:557-564

9. Meschia G, Cotter JR, Breathnach CS, Barron DH 1967 Simultaneous measurement of uterine and umbilical blood flows and oxygen uptake. Q J Exp Physiol 52:1-8

10. Wilkening RB, Anderson S, Martensson L, Meschia G 1982 Placental transfer as a function of uterine blood flow. Am J Physiol 242:H429-H436

11. Hay WW Jr, Myers SA, Sparks JW, Wilkening RB, Meschia G, Battaglia FC 1983 Glucose and lactate oxidation rates in the fetal lamb. Proc Soc Exp Biol Med 173:553-563

12. Crandell SS, Palma PA, Morriss FH Jr 1983 Umbilical glucose and lactate extractions during maternal hyperglycemia in sheep. Am J Physiol 244:R882-R887

13. Hay WW Jr, Meznarich HK 1989 Effect of maternal glucose concentration on uteroplacental glucose consumption and transfer in pregnant sheep. Proc Soc Exp Biol Med, 190:63-69

14. Widdas WF 1952 Inability of diffusion to account for placental glucose transfer in the sheep and consideration of the kinetics of a possible carrier transfer. J Physiol (Lond) 118:23-39

15. Simmons MA, Battaglia FC, Meschia G 1979 Placental transfer of glucose. J Dev Physiol 1:227-243

16. van Veen LCP, Teng C, Hay WW Jr, Meschia G, Battaglia FC 1987 Leucine disposal and oxidation rates in the fetal lamb. Metabolism 36:48-53

17. Johnson JD, Dunham L, Shipper BJ, Lottfield RB 1986 Protein turnover in tissues of the rat fetus following maternal starvation. Pediatr Res 20:12521257

18. Hay WW Jr, Sparks, JW, Gilbert G, Battaglia FC, Meschia G 1984 Effect of insulin on glucose uptake by the maternal hindlimb and uterus, and by the fetus in conscious pregnant sheep. J Endocrinol 100:119-124

19. Bloch CA, Banach W, Landt K, Devaskar S, Sperling MA 1986 Effects of fetal insulin infusion on glucose kinetics in pregnant sheep: a compartmental analysis. Am J Physiol 251:E448--E456 